\title{
Peningkatan kesadaran akan skrining non-invasif risiko prediabetes pada komunitas usia produktif
}

\author{
Iche Andriyani Liberty ${ }^{1}$, Pariyana ${ }^{1}$, Eddy Roflin ${ }^{1}$, Muhammad Aziz ${ }^{1}$, Mira Maulani Fatima ${ }^{2}$ \\ ${ }^{1}$ Bagian Kesehatan Masyarakat dan Kedokteran Komunitas, Fakultas Kedokteran, Universitas Sriwijaya, \\ Palembang, Indonesia \\ 2Pendidikan Profesi Dokter, Fakultas Kedokteran Universitas Sriwijaya, Palembang, Indonesia \\ E-mail: iche.aliberty@gmail.com
}

\begin{abstract}
Abstrak
Kelompok masyarakat usia produktif merupakan komunitas yang rentan untuk mengalami prediabetes. Salah satu solusi untuk meningkatkan kesadaran komunitas berisiko tersebut adalah dengan memberikan peningkatan pengetahuan yang komprehensif bahwa skrining dengan pengukuran TyG Index dan beberapa antropometri tubuh adalah bersifat non-invasif, mudah, dan murah untuk mencegah risiko prediabetes dan progresifitasnya. Metode pelaksanaan kegiatan pengabdian masyarakat ini yaitu pemberian motivasi berupa promosi kesehatan atau penyuluhan. Berdasarkan data yang diperoleh dari kegiatan yang telah dilakukan, dapat disimpulkan terdapat kecenderungan, bahwa mereka yang memiliki IMT yang tinggi cenderung memiliki TyG Index yang tinggi pula. Maka dari itu, disarankan agar pasien selalu menjaga dan memelihara berat badan dan lingkar perut pada batas normal sesuai usia. Serta melakukan pemeriksaan kadar glukosa darah, profil lipid, dan tekanan darah secara rutin di pelayanan kesehatan terdekat, seperti Posbindu atau Puskesmas. Peningkatan pengetahuan yang komprehensif bahwa skrining dengan pengukuran TyG Index dan beberapa antropometri tubuh seperti berat badan, tinggi badan, lingkar perut adalah bersifat non-invasif telah menjadi salah satu solusi untuk meningkatkan kesadaran komunitas usia produktif dalam mencegah risiko prediabetes dan diabetes mellitus.
\end{abstract}

Kata kunci: Skrining, Non-Invasif, Prediabetes

\begin{abstract}
Raising awareness of non-invasive screening of risk of prediabetes in productive age communities. Productive age groups of people are vulnerable to prediabetes. One solution to increase awareness of these risk communities is to provide comprehensive knowledge enhancement that screening with the measurement of the TyG Index and several body anthropometries is non-invasive, easy, and inexpensive to prevent the risk of prediabetes and its progression. The method of implementing this community service activity is providing motivation in the form of health promotion or counseling. Based on the data obtained from the activities that have been carried out, it can be concluded that there is a tendency that those who have a high BMI tend to have a high TyG Index as well. Therefore, it is recommended that patients always maintain and maintain their weight and abdominal circumference at normal limits according to age. As well as checking blood glucose levels, lipid profiles, and blood pressure regularly at the nearest health service, such as Posbindu or Puskesmas. Increasing comprehensive knowledge that screening with the measurement of the TyG Index and several body anthropometrics such as weight, height, and abdominal circumference is non-invasive and has become one of the solutions to increase awareness of the productive age community in preventing the risk of prediabetes and diabetes mellitus.
\end{abstract}

Key words: Screening, Non-Invasive, Prediabetes 


\section{PENDAHULUAN}

Prediabetes adalah suatu kondisi peningkatan glukosa darah, termasuk gangguan glukosa puasa dan gangguan toleransi glukosa (IGT), yang mendahului timbulnya diabetes mellitus tipe 2. Meskipun tanpa gejala, prediabetes merupakan faktor risiko independen untuk penyakit kardiovaskular dan jika tidak diintervensi kemungkinan akan konversi menjadi diabetes mellitus tipe 2.12 Diagnosis dini dan intervensi untuk prediabetes dapat mencegah atau menunda progresivitas penyakit.

Penilaian resistensi insulin dengan Hyperinsulinemic Euglycemic Clamp maupun Homeostasis Model Assessment Insuline Resistance (HOMA-IR) di komunitas pada negara berkembang seperti Indonesia masih belum praktis dan aplikatif dilaksanakan. ${ }^{2-4}$ Parameter antropometri dan laboratorik yang dapat dikembangkan menjadi marker potensial untuk menilai resistensi insulin adalah Triglycerides Glucose Index (TyG Index) dan beberapa antropometri tubuh seperti berat badan, tinggi badan, lingkar perut belum banyak diketahui oleh masyarakat, terutama komunitas usia produktif yang masih merasa mempunyai kondisi kesehatan fisik yang optimal.

Pengabdian kepada masyarakat merupakan tugas Tri Dharma Perguruan Tinggi. Wujud pengabdian kepada masyarakat adalah dengan memberikan sosialisasi mengenai bagaimana meningkatkan kesadaran akan skrining non-invasif risiko prediabetes pada komunitas usia produktif. Diharapkan kegiatan pengabdian ini bermanfaat untuk masyarakat dan penyedia layanan kesehatan dalam melakukan upaya pencegahan penyakit prediabetes dan progresivitasnya.

\section{TINJAUAN PUSTAKA}

Kelompok masyarakat usia produktif merupakan komunitas yang rentan tetapi belum menyadari bahwa mereka adalah kelompok berisiko untuk mengalami prediabetes. Data Riset Kesehatan Dasar (Riskesdas) menunjukkan bahwa sekitar separuh atau 50\% dari populasi Indonesia berumur 25-34 tahun memiliki tanda-tanda prediabetes dan angka 
tersebut lebih besar lagi pada kelompok umur 35-44 tahun atau 60\%. Data tersebut membuktikan 3 dari 5 orang berusia 35 - 44 tahun di Indonesia menderita prediabetes. ${ }^{5}$

Di era Jaminan Kesehatan Nasional (JKN), diabetes menyumbang pengeluaran keuangan penyakit kronis dengan biaya yang besar. ${ }^{6}$ Rata-rata biaya untuk 1 pasien kardiovaskuler setahun adalah Rp.40.632.776, dan terjadi peningkatan jumlah pasien baru 9.697 per tahun. Sehingga proyeksi untuk pembiayaan pelayanan kesehatan 1 pasien dengan penyakit kardiovaskular dalam satu tahun, membutuhkan 1.593 peserta sehat atau membutuhkan 15.447.321 peserta sehat untuk membiayai pelayanan kesehatan penambahan pasien baru dengan penyakit kardiovaskular dalam satu tahun. ${ }^{7}$ Kontributor utama tantangan pengendalian diabetes adalah bahwa 30-80\% penderita diabetes tidak terdiagnosis. ${ }^{1}$ Prediabetes adalah "golden period" dalam mencegah dan atau menunda konversi status glukosa menjadi diabetes, tetapi sangat progresif untuk mengalami komplikasi dikemudian hari. ${ }^{8}$

Periode induksi ini merupakan waktu yang harus menjadi perhatian agar dapat mengembangkan upaya pencegahan yang optimal. Penilaian resistensi insulin merupakan "fundamental goal" dalam penelitian epidemiologi penyakit diabetes karena mempunyai nilai prevensi yang besar. Penilaian dampak potensial atas suatu program skrining tentu dapat digunakan untuk memperkirakan efek strategi pencegahan dan intervensi. ${ }^{269-11}$

Hasil penelitian yang dilakukan Liberty, et al (2018) menunjukkan bahwa nilai AR\% atau dampak potensial dari pengukuran TyG Index pada subjek prediabetes untuk tercegah mengalami progresivitas menjadi diabetes mellitus adalah 80,67\%. Dampak potensial yang tinggi tersebut dimungkinkan terjadi karena TyG Index mempunyai akurasi yang tinggi sebagai marker prediabetes. Sehingga salah satu solusi untuk meningkatkan kesadaran komunitas berisiko tersebut adalah dengan memberikan peningkatan pengetahuan yang komprehensif bahwa skrining dengan pengukuran TyG Index dan beberapa antropometri tubuh seperti berat badan, tinggi badan, lingkar perut adalah bersifat non-invasif, mudah, dan murah untuk mencegah risiko prediabetes. 


\section{METODE}

Kegiatan Pengabdian kepada Masyarakat dilaksanakan pada Kamis, 31 Oktober 2019 bertempat di Fakultas Kedokteran Universitas Sriwijaya (FK Unsri) yang melibatkan 10 orang kader PTM (Penyakit Tidak Menular) dari Puskesmas Sekip, 10 orang Kader PTM FK Unsri, dan 30 orang penduduk usia produktif yang berdomisili di wilayah kerja Puskesmas Sekip.

Metode pelaksanaan kegiatan pengabdian masyarakat ini yaitu pemberian motivasi berupa promosi kesehatan/penyuluhan yang berkaitan dengan hal-hal yang dapat meningkatkan kesadaran komunitas berisiko tersebut adalah dengan memberikan peningkatan pengetahuan yang komprehensif bahwa skrining dengan pengukuran TyG Index dan beberapa antropometri tubuh seperti berat badan, tinggi badan, lingkar perut adalah bersifat non-invasif, mudah, dan murah untuk mencegah risiko prediabetes.

\section{HASIL DAN PEMBAHASAN}

Kegiatan pengabdian masyarakat meliputi kegiatan penyuluhan tentang cara mudah untuk mecegah risiko prediabetes. Penyuluhan dilakukan untuk menjelaskan kepada pasien tentang pentingnya skrining pengukuran kadar glukosa darah dan trigliserida darah yang selanjutnya akan didapatkan TyG Index yang mempunyai akurasi tinggi sebagai marker dan beberapa antropometri sebagai upaya untuk mencegah risiko prediabetes.

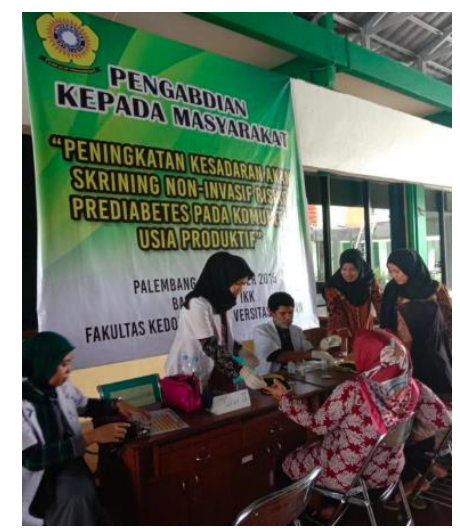

Gambar 1. Pelaksanaan kegiatan skrining 
Penilaian kesadaran masyarakat akan skrining prediabetes dilakukan dengan menggunakan kuesioner yang berisi pertanyaan-pertanyaan mengenai pengetahuan tentang skrining risiko prediabetes dengan TyG Index serta beberapa antropometri tubuh seperti berat badan, tinggi badan, dan lingkar perut. Penyuluhan dan pemberian kuesioner melibatkan mahasiswa Fakultas Kedokteran yang sedang melakukan pendidikan kepaniteraan yang dilakukan di Bagian IKM IKK Fakultas Kedokteran Universitas Sriwijaya.

Peserta yang mengikuti kegiatan ini berjumlah 30 orang yang terdiri atas 8 orang atau 26,7\% pria dan 22 orang atau 73,3\% wanita. Hasil pengukuran secara lengkap disajikan pada Tabel 1.

Tabel 1. Distribusi frekuensi TyG Index dan antropometri

\begin{tabular}{|c|c|c|c|c|c|c|c|}
\hline TyG Index & $\begin{array}{c}\text { Usia } \\
\text { (Tahun) }\end{array}$ & $\begin{array}{c}\text { Berat } \\
\text { Badan } \\
(\mathrm{kg})\end{array}$ & $\begin{array}{c}\text { Tinggi } \\
\text { Badan } \\
\text { (cm) }\end{array}$ & $\begin{array}{c}\text { IMT } \\
\left(\mathrm{kg} / \mathrm{m}^{2}\right)\end{array}$ & $\begin{array}{c}\text { Lingkar } \\
\text { Perut } \\
\text { (cm) }\end{array}$ & GDS (mg/dL) & $\begin{array}{c}\text { Trigliserid } \\
(\mathrm{mg} / \mathrm{dL})\end{array}$ \\
\hline Normoglikemik & 41,82 & 63,55 & 158,32 & 25,55 & 83,45 & 81,36 & 115,64 \\
\hline Prediabetes & 42,39 & 63,06 & 158,89 & 25,06 & 83,83 & 133,78 & 134,11 \\
\hline
\end{tabular}

\section{SIMPULAN}

Berdasarkan data tersebut di atas, dapat disimpulkan terdapat kecenderungan, bahwa mereka yang memiliki IMT yang tinggi cenderung memiliki TyG Index yang tinggi pula. Oleh karena itu, disarankan agar pasien selalu menjaga dan memelihara berat badan dan lingkar perut pada batas normal sesuai usia. Pasien juga sebaiknya melakukan pemeriksaan kadar glukosa darah, profil lipid, dan tekanan darah secara rutin di pelayanan kesehatan terdekat, seperti Posbindu atau Puskesmas. Peningkatan pengetahuan yang komprehensif bahwa skrining dengan pengukuran TyG Index dan beberapa antropometri tubuh seperti berat badan, tinggi badan, lingkar perut yang bersifat non-invasif telah 
menjadi salah satu solusi untuk meningkatkan kesadaran komunitas usia produktif dalam mencegah risiko prediabetes dan diabetes mellitus.

\section{Ucapan Terima Kasih}

Ucapan terima kasih ditujukan kepada mahasiwa dan teman-teman sejawat yang sudah membantu pada kegiatan ini serta Universitas Srwiwijaya yang telah membiayai kegiatan ini. Dana kegiatan berasal dari Universitas Sriwijaya Berdasarkan Surat Keputusan Rektor Universitas Sriwijaya Nomor: 0008/UN9/SK.LP2M.PM/2019 tanggal 23 Agustus 2019.

\section{Referensi}

1. IDF. Diabetes Voice, Global Perspektives on Diabetes. 2017;(2 July).

2. Liberty IA, Putri NK. Association between triglyceride-glucose index (Tyg index) and type 2 diabetes mellitus: A systematic review. Epidemiol Biostat Public Heal. 2020;17(1): 1-6.

3. Park SY, Cho YJ, Lee SR, Chung H, Jeong K. Triglyceride is a useful surrogate marker for insulin resistance in Korean women with polycystic ovary syndrome. Yonsei Med J. 2015;56(3): 785-92.

4. Vasques ACJ, Novaes FS, de Oliveira M da S, Matos Souza JR, Yamanaka A, Pareja JC, et al. TyG index performs better than HOMA in a Brazilian population: A hyperglycemic clamp validated study. Diabetes Res Clin Pract. 2011;93(3): 8-10.

5. Ministry of Health Republic of Indonesia. Basic health research report of Indonesia year 2018 (Laporan Nasional Riskesdas 2018). Riskesdas 2018. 2018.

6. Iche Andriyani Liberty. Triglyceride glucose index merupakan prediktor marker diagnostik konversi prediabetes yang akurat pada wanita urban usia reproduktif. 2018.

7. Idris F. Pembiayaan pelayanan kesehatan penyakit kronis dan Katastropik Era JKN di Rumah Sakit: Disampaikan pada seminar nasional PERSI dan Palembang Hospital Expo "produktivitas dan efisiensi pengelolaan RS di era JKN dan MEA." BPJS RI. 2017.

8. Liberty IA, Kodim N. Assess prediabetes risk, as a golden period for prevention of diabetes. Asian J Pharm Clin Res. 2017;10(6): 349-53.

9. Navarro-González D, Sánchez-Íñigo L, Pastrana-Delgado J, Fernández-Montero A, Martinez JA. Triglyceride-glucose index (TyG index) in comparison with fasting plasma glucose improved diabetes prediction in patients with normal fasting glucose: The vascular-metabolic CUN cohort. Prev Med (Baltim). 2016;86: 99-105.

10. Zhang M, Wang B, Liu Y, Sun X, Luo X, Wang C, et al. Cumulative increased risk of incident type 2 diabetes mellitus with increasing triglyceride glucose index in normal-weight people: The rural Chinese cohort study. Cardiovasc Diabetol. 2017;16(1): 1-11.

11. Tabák AG, Herder C, Rathmann W, Brunner EJ, Kivimäki M. Prediabetes: A high-risk state for diabetes development. Lancet. 2012;379(9833): 2279-90. 